\title{
Niñez y migración: Concepciones sobre los derechos sociales en la escuela*
}

\section{Childhood and migration: social rights conceptions at school}

Investigación

Laura Victoria Martínez

Universidad de Buenos Aires lauvicmartinez@yahoo.com.ar

Recibido: 31 de marzo de 2016 / Aceptado: 13 de junio de 2016

\section{Resumen}

Este trabajo se propone aportar al estudio de los derechos sociales de los niños y niñas migrantes en la escuela, desde una perspectiva antropológica que se interrogue sobre el punto de vista normativo. Para ello se presentan resultados de una etnografía escolar en una institución pública primaria de la zona sur de la Ciudad de Buenos Aires, y se analizan las concepciones de los docentes en torno a la inclusión de estos niños/as en la escuela pública. Atendiendo en particular al protagonismo de las necesidades y merecimientos de la niñez en un contexto en el que se expresan cuestionamientos al usufructo de otros derechos sociales a los que las familias acceden con los certificados de escolaridad, se aborda la disociación entre las necesidades de los niños y las de sus familias. Las reflexiones teóricas sugieren tensiones entre la jerarquización de los derechos sociales de la niñez y las clasificaciones morales, que tienden a despolitizar las necesidades de los colectivos migrantes.

Palabras clave: Derechos del niño, migración, derechos sociales, etnografía, escolaridad.

\begin{abstract}
This paper aims to contribute to the study of the social rights of migrant children in school, from an anthropological perspective that questions policy perspectives. It analyzes the results of a primary school ethnography in a public institution in the south of the City of Buenos Aires, and it analyses the assumptions of teachers regarding the inclusion of these children I as in public school, with particular attention to the role of the needs and merits of children in a context in which challenges to the enjoyment of other social rights are expressed and analyzed to reach families with school certificates. Theorethical reflections suggest tensions between the hierarchy of children's social rights and moral classifications, and the way these processes tend to depoliticize the needs of migrant groups.
\end{abstract}

Keywords: Children's rights, migration, social rights, ethnography, education.

* Este artículo forma parte del proyecto doctoral: La experiencia escolar de niños migrantes. Procesos de identificación y concepciones sobre los derechos económicos y sociales, financiado por el Consejo Nacional de Investigaciones Científicas y Técnicas (CONICET).

Forma sugerida de citar: Martínez, Laura (2016). Concepciones sobre los derechos sociales en la escolaridad de la niñez migrante. Alteridad, 11(1), pp. 10-20. 


\section{Introducción}

En el ámbito argentino, hay un consenso en reconocer la ruptura histórica que implicó la ley de migraciones 25.871 del año 2004, tanto por el abandono de las perspectivas de seguridad hacia un paradigma de derechos humanos, como por la generación de una nueva categoría de residencia para habitantes del Mercosur (Domenech, 2007; Pacecca y Courtis, 2010; Ceriani Cernadas, 2011). Un aspecto que suele asociarse a esta reforma es el aumento considerable de la proporción de migrantes regularizados y la agilización de los trámites relativos mediante la implementación del programa Patria Grande, aunque desde luego no ha sido un proceso lineal (Informe Anual CELS, 2012). Un tercer aspecto que suele destacarse es que la letra de la ley avanza en la cuestión central del reconocimiento de ciertos derechos sociales independientemente de la condición de regularidad, como el acceso a salud y educación ${ }^{1}$.

Registrando la incongruencia entre las prácticas y las normativas reconocidas, las reflexiones sobre el "proceso de implementación" del paradigma de derechos de las personas migrantes en Argentina se orienta fundamentalmente por el enfoque normativo, que analiza las prácticas de los agentes estatales en términos de la vulneración y/o la efectivización de los derechos. En este sentido se vienen pronunciando un conjunto de actores institucionales y activismos que desde la sanción de la ley han desarrollado diversas iniciativas y sostenido mecanismos de articulación con el estado, como marco del seguimiento de la implementación de la ley de migraciones. En el marco de estos activismos, la articulación con UNICEF ha promovido una retórica en torno a los niños migrantes como sujetos de derechos (UNLa-UNICEF, 2013).

El relevamiento de problemáticas que afectan a los niños migrantes -e hijos de migrantesse vincula con las reflexiones sobre la implemen-

La cuestión migratoria ha comenzado a ser incorporada en las normativas sobre derechos educativos, como la Ley de Educación Nacional (Ley 26206/2006), ya reconocidos desde el año 1999 en la Ciudad de Buenos Aires en la ley 203/1999 (Cerrutti y Binstock, 2012). tación del paradigma de derechos de migrantes en términos más generales. En esta línea, se han señalado los asuntos pendientes en materia de adecuación del conjunto del ordenamiento jurídico a la ley de migraciones (Ceriani, Cyment y Morales, 2011), pero sobre todo una serie de problemáticas dentro de las instituciones con las que interactúan los migrantes (hospitales, escuelas, acceso a la justicia, entre otros). Estos procesos imponen reconocer las tensiones entre la igualdad jurídica entre nacionales y extranjeros que reconoce la ley de migraciones vigente, y la desigualdad que imponen las decisiones burocráticas y administrativas en distintos ámbitos del Estado (Gil Araujo et al., 2013). En este sentido, en los últimos años se vienen documentando prácticas cotidianas que obstaculizan el cumplimiento y acceso de garantías que están contempladas en la letra de la ley (Ceriani, García y Gómez, 2014).

Desde el enfoque jurídico también se ha señalado que la forma en que se definen determinadas políticas públicas puede generar mecanismos excluyentes para los migrantes y sus hijos. Una política particularmente debatida en este ámbito es la exigencia de plazos de residencia en la prestación de la Asignación Universal por Hijo (AUH), -tres años además de la regularización del status migratorio (Ceriani et al., 2011)-. Por un lado, este debate permite evidenciar la persistencia de desigualdad jurídica entre nacionales y extranjeros en una política que se presenta como superadora de los programas focalizados (Ceriani Cyment y Morales, 2011; CELS, 2012). Pero asimismo, la argumentación jurídica que disputa los criterios que restringen el percibimiento de la AUH permite observar el entrecruzamiento con otro paradigma de derechos: el de los niños. En el ámbito argentino, el niño migrante se construye como un sujeto de derechos en el que confluyen dos marcos normativos (de infancia y migración) que deben ser articulados para saldar "el doble déficit" que en cada uno se registra sobre el otro: el paradigma legal de infancia no contempla los procesos migratorios, mientras que la ley y dispositivos en materia migratoria no abordan la condición de la niñez y la adolescencia (Ceriani, García y Gómez, 2014). 
Proponemos dialogar con esta perspectiva desde un abordaje que apuesta al registro de las experiencias concretas de quienes son nombrados en las retóricas de derechos. Privilegiando los significados que construyen los sujetos con quienes interactuamos - principalmente en torno a dos estrategias metodológicas tradicionalmente asociadas al enfoque etnográfico, como la observación participante y entrevistas abiertas o no directivas- (Guber, 1991). En este marco, reconstruimos algunos ejes de análisis en torno a las categorías sociales, fundamentales para acceder a lo no documentado que se intenta registrar desde la etnografía (Rockwell, 2009), deteniéndonos en los sentidos que docentes y directivos de la escuela construyen en su interacción con los niños migrantes y sus familias, específicamente en torno a lo que denominamos como la interpretación de los derechos sociales en la escuela.

\section{Inclusión educativa, infancia y desigualdad}

La escuela en la que trabajamos es una institución de nivel primario pública, ubicada en una calle lindera a una de las villas ${ }^{2}$ de la zona sur de la Ciudad de Buenos Aires.

Nuestra inserción en este territorio considera una serie de características sociodemográficas, sociales y educativas que lo constituyen como un ámbito sumamente relevante para indagar el cruce entre los procesos migratorios, la escolaridad y otros derechos sociales. En tal sentido, esta parte de la Ciudad concentra una alta proporción de población migrante de países limítrofes y del Perú ${ }^{3}$, pero asimismo una histórica y generalizada demanda por vivienda digna y necesidades bási-

2 Sabemos que existe un debate en torno a esta denominación para el caso de los niños que son hijos de migrantes, sin embargo desde el enfoque de derechos se los incluye en un mismo paradigma ya que se atiende a la forma en que la ciudadanía de los niños es atravesada por los procesos migratorios, propios o familiares.

3 En particular, la villa a la que hace referencia este trabajo condensa una proporción de habitantes de origen boliviano y paraguayo muy superior a la media de la Ciudad (Novaro y Beheran, 2011, p. 151). cas insatisfechas. También la desigualdad educativa adquiere un peso específico en la jurisdicción a la que pertenece la escuela en la que trabajamos, donde más se utiliza el sistema de educación pública y donde reside el $74 \%$ de los niños pobres de la Ciudad (Blanck, 2013).

A partir de nuestra entrada en el año 20124, comenzamos a indagar en descripciones generales sobre el trabajo cotidiano con niños/as y familias. Varios docentes han enfatizado características que supuestamente distinguen a esta institución por sobre las otras, en particular las buenas condiciones edilicias, la diversidad de proyectos pedagógicos impulsados por la gestión directiva (espacios de educación en artes que se ofrecen dentro de la jornada escolar) y la continuidad de algunos docentes, un "elenco estable" (de acuerdo a la definición de una maestra con más de siete años de trabajo sostenido en la institución).

La retórica de la inclusión forma parte de los discursos desde los que se legitima la presencia de los niños y niñas en la escuela, aunque más allá de este contexto en particular, se reconoce que la inclusión se ha convertido en una categoría protagonista en los discursos educativos (Novaro, 2012).

Sin embargo, es un camino obligado profundizar en la contextualización de dicha retórica, y cómo se articula a mandatos tradicionalmente asociados a la escuela, como la socialización de la infancia y la transmisión de saberes socialmente legitimados: comenzamos a atender este aspecto a partir del énfasis que la mayoría de los/as entrevistados/as atribuye a la jerarquización de contenidos y saberes a enseñar en distintos proyectos, planificaciones. De hecho, escuchamos cuestionamientos explícitos a lo que se interpretan como prácticas y discursos de "bajar las expectativas" en los espacios educativos a los que asiste población en condiciones de pobreza.

Sostenemos que resulta por demás auspicioso que se discutan concepciones y prácticas que diversos estudios han definido como mecanismos de diferenciación y devaluación de los circui-

4 Conversamos con un total de 12 docentes de grado de entre 30 y 45 años. Todos sus nombres han sido cambiados. 
tos educativos por los que transita la población migrante limítrofe y pobre en general (Neufeld y Thisted, 1999; Novaro, 2012); discursos que se involucran por ejemplo, en la toma de decisiones por parte de la directora ante personal docente temporario cuyo desempeño no es evaluado como satisfactorio "hay cosas que no negocio".

Estos discursos institucionales sobre lo que se "ofrece" dentro del establecimiento, no pueden disociarse de las concepciones que se construyen sobre las experiencias de los/as niños/as fuera de ella. La escuela no sólo es presentada como el acceso a la movilidad social y la acreditación educativa, sino que también aparece como el contraste de los entornos y experiencias negativas que niños/as vivencian en la villa.

(...)...una realidad que no pueden dormir, porque el vecino se lo pasa escuchando cumbia, que hay tiros, que no alcanza la plata... (...) y vos le das la oportunidad de mostrarle que hay otra realidad... (basándote) en el contenido, abrirles la cabeza...(...) (Entrevista Patricia, 17/09/12).

Si es válido afirmar que los niños aparecen como sujetos protagonistas de las retóricas de inclusión educativa, es importante considerar a los "derechos de los niños" como un lenguaje legitimado en los discursos y las prácticas de los docentes. En nuestros acercamientos comenzamos a registrar estas categorías en las memorias fotográficas de talleres dictados y actos escolares, en afiches de las paredes del establecimiento, y asimismo en proyectos pedagógicos de algunas docentes con quienes intercambiamos. Reconstruimos ciertos indicios en torno al protagonismo de los niños en las iniciativas que se llevan adelante en la institución cuando se nombran "derechos".

Hasta aquí no hemos dicho nada original; se sabe que el paradigma de derechos de la infancia ha venido ganando terreno en los lineamientos educativos. No obstante, es importante tener en cuenta el protagonismo de este discurso cuando conversamos con las/os docentes sobre los derechos sin imponer de antemano el "sujeto niño" en diversas situaciones (en descripciones sobre su trabajo cotidiano en la institución, o en una conversación previa a una clase sobre los derechos humanos como contenido curricular). Si acordamos en que la politicidad del discurso de derechos se despliega cuando es fijado a un sujeto o identidad que funcione como un "significante flotante" (Douzinas, 2006), resulta relevante destacar el protagonismo de la niñez (sus derechos a la identidad, a la recreación, a la educación, entre otros) no solamente en los lineamientos institucionales, sino como "clave" de interpretación de nuestra pregunta por "los derechos en la escuela" en los intercambios con algunos docentes.

En resumen, los significados que hemos reconstruido nos permiten reconstruir ciertas "retóricas de deber ser" de la institución escolar: la inclusión educativa, la calidad pedagógica, la promoción de los derechos de la niñez. Pero asimismo, en la descripción del trabajo cotidiano, aparecen otras concepciones de deber ser que no se dirigen a la institución escolar sino a las familias. En adelante avanzaremos en los sentidos que se atribuyen a la escuela como un escenario de intersección entre derechos sociales.

\section{La construcción de las exigencias y necesidades legítimas: la escuela entre los (otros) derechos sociales}

Sabemos que la escuela es un escenario en el que se despliegan numerosas prácticas relativas a la efectivización de políticas públicas: certificaciones para los programas de transferencia de ingresos (como la Asignación Universal por Hijo "AUH"), provisión de útiles escolares y netbooks a los estudiantes (mediante el programa nacional "Conectar Igualdad”, cuya réplica en Ciudad de Buenos Aires se denomina "Plan Sarmiento"). Avanzando en los interrogantes que habíamos planteado en una investigación precedente en la misma institución, (Martinez, 2011) exploramos detenidamente la forma en que los agentes educativos atribuyen sentidos a esta trama de burocracias que atraviesa el espacio escolar. 
En primer lugar, la escuela es un espacio en el que se concretan programas estatales de atención a la infancia de diverso alcance, como un programa que controla la salud visual en niños de los primeros grados y organiza la distribución de anteojos para los casos que se detecten en la escuela. En este sentido se reconoce que: "La escuela termina siendo el lugar de lo público: vacunas, libreta, salud visual..." (Entrevista, Sara, 30/09/13).

Ante el relato de interacciones que se sostienen con las familias, permanentemente se demarca una diferencia entre lo que "corresponde" que se le reclame a la escuela y lo que no. Se relata con satisfacción que una madre consulte al docente de su hijo sobre los criterios pedagógicos elegidos para la explicación de determinado tema, mientras se demarca la incompetencia de las consultas y pedidos en torno a otras "áreas": "Yo a la gente le tengo que decir que la escuela es para estudiar: (como enumerando) no es centro de salud, no es policía federal, no es centro de informes (...)" (Directora, conversación 20/5/15).

Indudablemente, estas palabras dan cuenta de las problemáticas que condicionan a las escuelas que están emplazadas en estos territorios, con una alta concentración de desigualdades estructurales. La permanente enunciación de "los límites" en las responsabilidades de la escuela en torno a lo que en ella se identifica como "pedagógico" remite a las tensiones que se construyen entre las dimensiones asistencial y pedagógica de la institución escolar.

Por un lado, los condicionamientos y privaciones que atraviesan a los niños/as y a la población migrante en general, son imágenes presentes en los relatos de los maestros/as sobre las experiencias de migración y el deseo de movilidad social ascendente de las familias. Es frecuente que se resalte la voluntad de sacrificio de los migrantes, e incluso se reconozcan las múltiples problemáticas que atraviesan en Argentina -como las condiciones de informalidad en nichos laborales asociados a determinados colectivos nacionales- 5 .

5 Aunque es importante recordar que este modo particularmente "mediático" de definir el problema de la explotación laboral suele caer en la extranjerización de problemáticas que son en cambio, estructurales (Gil Araujo et al., 2013).
Por un lado, en la mirada sobre las familias (principalmente bolivianas ya que es la población con más presencia en la matrícula escolar) aparece recurrentemente la referencia al esfuerzo de esta población por las largas jornadas de trabajo que deben completar y la preocupación porque sus hijos puedan acceder a acreditaciones educativas para la inserción en el mercado de trabajo formal, las expectativas de movilidad social ascendente.

(...) los que vinieron al país piensan (...) que ellos van a ser los últimos que van a tener ese tipo de trabajo esclavo o semi-esclavo y que el sacrificio lo hacen para que su hijo en algún momento pueda tener algún crecimiento o despegarse de la clase baja (...) (Entrevista Darío, docente 7mo.16/08/13).

Por otro lado, es significativo que se describa a esta población desde extremos opuestos, ya que además de aparecer como víctimas de explotación laboral, otros sujetos son caracterizados como "chantas" - por los mismos interlocutores que enfatizan dicha explotación- al afirmar que se "argentinizaron". Cuando se habla de "argentinización" no se está haciendo mención alguna a documentos de residencia o el trámite legal de nacionalización para obtener el DNI argentino, aunque cuando se menciona "la argentinización" de cierta parte de los migrantes también suele enfatizarse que se trata de las "segundas generaciones", es decir de los hijos de los migrantes o de quienes llevan muchos años en Argentina.

Para intentar descifrar qué se entiende por argentinización, es preciso destacar que a los argentinos de la villa, -en ocasiones sospechados de "buscar el camino fácil" del acceso a los programas de subsistencia del Estado- se los suele describir en contraposición a las características positivas que se atribuyen a los migrantes que "llegan" con voluntad de sacrificio y un proyecto de progreso (social y económico) familiar. En este sentido, los argentinos también suelen ser quienes contrastan con las imágenes sobre la población boliviana como "respetuosa de la escuela y el maestro", muchas veces vinculada a cierto estereotipo sobre la "sumisión" y los estilos comunicati- 
vos asociados a una forma de hablar pausada y en voz relativamente baja.

Ante este marco de apreciaciones nos parece importante preguntarnos por la fuerza de estas polarizaciones en las interpretaciones de los derechos sociales que construyen los docentes, como agentes estatales que interactúan con los destinatarios de las políticas.

En una institución donde los actores educativos expresan su preocupación por el bienestar, la protección y las oportunidades que deben garantizarse a los niños, nos parece interesante detenernos en los discursos en torno a la $\mathrm{AUH}^{6}$. Se puede inscribir a esta prestación dentro de las políticas de transferencia condicionada de ingresos, en la medida en que para su efectivización se exige el cumplimiento de determinadas condicionalidades. En el caso de la AUH, los adultos deben presentar la libreta sanitaria al día con el calendario oficial de vacunación y los certificados de escolaridad (Feijoo y Corbeta, 2015).

Cuando escuchamos hablar de la AUH en la escuela, se reitera una misma categoría que condensa diversas miradas en torno a la asistencia estatal a las poblaciones más empobrecidas: "el Estado les da". En algunos casos, (es importante resaltar que no en todos), esta expresión fue desplegada en el contexto del cuestionamiento a lo que en el discurso público suele denominarse como "planes sociales" y dentro de lo cual suele incluirse a la AUH. En este punto es importante preguntarse cómo los agentes estatales construyen condicionalidades más amplias que las propias definiciones políticas:

Yo te digo siempre esto: si yo hubiera dado planes, en un año o en dos años le exigiría a esa gente que devuelva lo que se le dio pero en producción cada dos años: bueno, ya tuviste dos años de plan, estos dos años que siguen vos tenés que... no sé, trabajar y demostrar de alguna manera lo que estás produciendo, y tenés que mejorar tu

6 La asignación universal por hijo se define como una política superadora de los programas focalizados, que procura un piso de protección social (Feijoo Corbetta, 2015) para los sectores que están por fuera del sistema de seguridad social contributiva (Ceriani, 2011). forma de vivir. O sea obligarlos a que no es darle, darle, darle (...) (Entrevista Silvia, 3/10/13).

Lo que nos interesa destacar es que "el manto de sospechas" que pesa sobre las transferencias de ingresos a las familias se despliega en el mismo contexto en el que se detallan con preocupación las problemáticas y privaciones que afectan a los niños con los que se trabaja, inclusive en los "casos extremos" en los que esas privaciones involucran una adecuada alimentación.

(Cuando) la cito a la mamá de este nene que viene con hambre (...) yo la miro y ya es diferente. Viene con otra actitud corporal (...) diferente al resto de las madres (...) viene hasta con una cuestión corporal de vencida. El bebé viene (...) lo alzás y está con olor a sucio (...) es su abandono que lo extiende, es el abandono de ella y es también el no encontrarle el sentido a la vida.

(La docente con la que conversa le dice que también es que no saben qué herramientas tienen "para salir de eso") Hasta ahí lo de las herramientas, del plan; porque (...) para el plan no falta nadie. Todos te piden el certificado (...) Yo creo que es el abandono, y saber que hay cosas que están, que van a estar. Y ante eso van: esta señora también tiene el plan de ella, el plan de la nena, el plan... (Entrevista, Nora 3/10/13).

En este contexto, en el que los agentes educativos no son indiferentes a la privación económica de los niños y sus familias, puede explicitarse de forma superpuesta la preocupación por las necesidades básicas insatisfechas de un niño, -y las estrategias de la escuela para apoyar la alimentación del niño, quien perdió la vacante del comedor comunitario al que asistía, y ahora sólo puede comer "algo como" almuerzo cuando acompaña a su madre en un puesto de venta en la feria del barrio- y la relativización del impacto de dichas necesidades cuando interpreta las prácticas de su madre, a quien se atribuye predisposiciones moralmente cuestionables ("el abandono", pero también "saber que hay cosas que van a estar", como los planes sociales). Estas apreciaciones sobre la "desidia" de la madre, entonces, acompañan el relato de las dificultades 


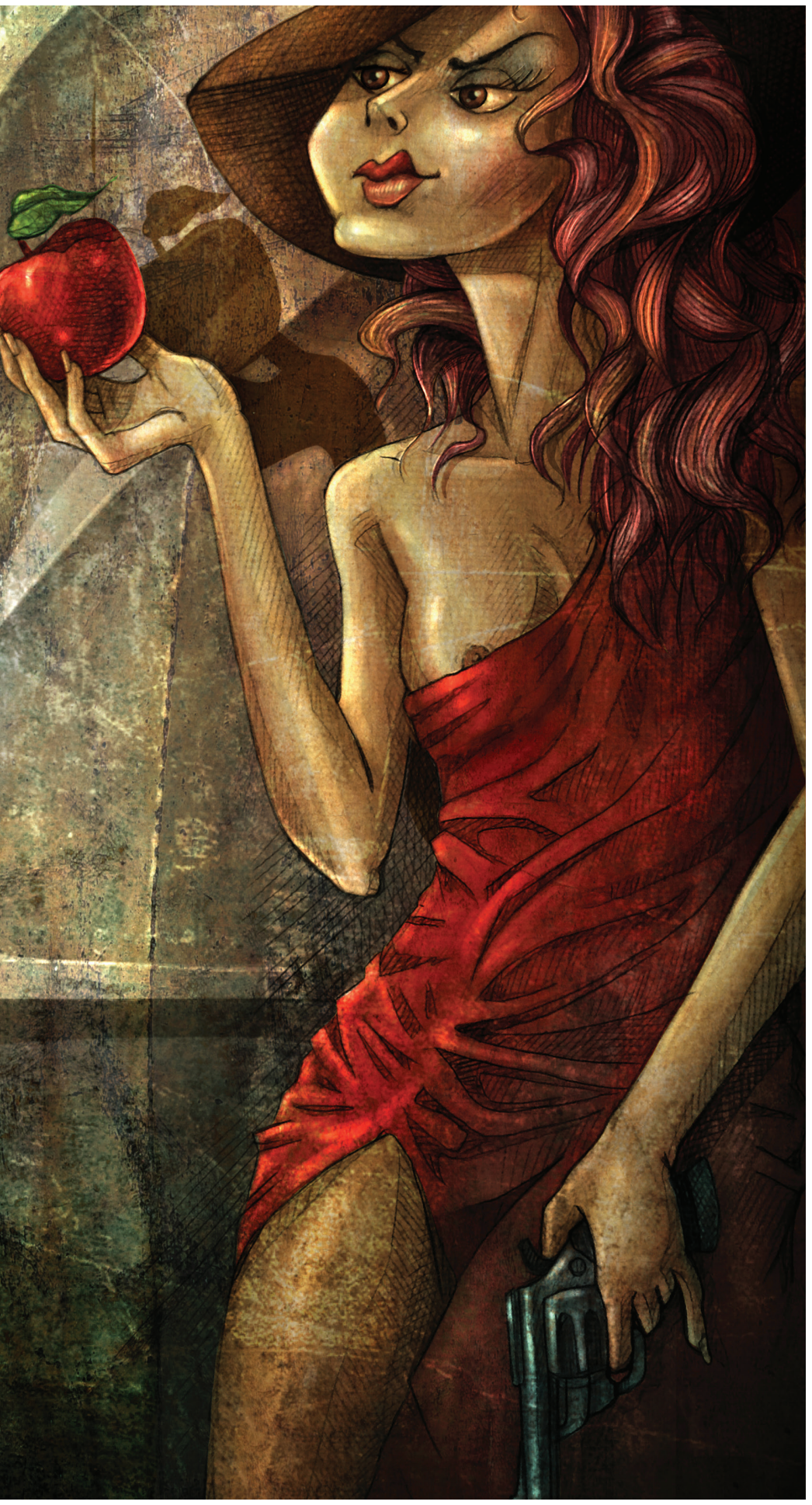

Minga

Mixta/ Lápiz sobre papel

y retoque digital. socioeconómicas que afronta la familia del niño en cuestión y las diversas estrategias de subsistencia que diariamente despliegan sus padres -la inestabilidad laboral del padre como trabajador temporario, las múltiples ocupaciones de la madre con varios hijos-.

En las descripciones sobre las condiciones de vida de la población que asiste a la escuela, abundan las imágenes con las que se asocia a las villas como símbolo de la pobreza en los ámbitos urbanos: la "inseguridad", la escasez de ingresos de las familias, las precarias condiciones habitacionales, la explotación laboral entre otras. En este sentido, el relato sobre las villas se vincula con las problemáticas que suelen entrar dentro del discurso público y mediático sobre estos asentamientos: la delincuencia, el hacinamiento de las viviendas, el consumo y negocio de drogas. Vale decir que en general, no registramos en estas descripciones aquello que no puede traducirse en imágenes: las responsabilidades institucionales incumplidas. Recordamos que los territorios de las villas también son nombrados en términos del incumplimiento de derechos sociales en los territorios de la zona sur de la Ciudad. En principio, nos remitimos al discurso jurídico de los activismos de derechos humanos y sociales con una sostenida inserción en demandas colectivas y relevamientos de problemáticas. Pero también a las organizaciones villeras del sur de la Ciudad que discuten la estigmatización mediática y disputan la definición de los problemas que atraviesan a las villas, visibilizándolas como demandas hacia el estado porteño.

Hasta aquí sugerimos ciertos contrapuntos entre las concepciones de los docentes y las que prevalecen en los lenguajes jurídicos y de reivindicación de derechos. Desde luego, esta suerte de "contraste" no es el punto de llegada sino el punto de partida: ya que es un supuesto que las políticas y lineamientos estatales son apropiados y resignificados por los agentes en los contextos de interacción específicos, en las prácticas institucionales. 
No obstante, el recurso a un ejercicio de "contrastación" entre estos lenguajes sobre un mismo territorio contribuye a echar luz en la pregunta por la enunciación del deber ser de las instituciones, frente a los más o menos explícitos cuestionamientos sobre el deber ser de los individuos (su falta de predisposición al trabajo, pero también el cuestionamiento a sus formas de crianza). Asimismo, lo que nos (pre)ocupa es la forma en que estas concepciones puedan contribuir a la construcción de percepciones naturalizadas sobre la desigualdad social, que oscilan entre el reconocimiento de la privación económica, por un lado y la atribución de exigencias a los habitantes de la villa, por otro. Teniendo en cuenta esta diversidad de lenguajes "en competencia" sobre las necesidades y merecimientos legítimos (Fraser, 1999), advertimos que la reiterada visibilización de lo que el Estado "da" a la población de la villa se produce en un contexto escolar donde sus condiciones de vida no suelen ser enunciadas en términos de lo que el Estado "debe".

En adelante nos preguntamos por las tensiones que pueden reconstruirse entre los merecimientos que se reconocen a la niñez, y los cuestionamientos que paralelamente se dirigen al usufructo de prestaciones sociales por parte de las familias, explorando esta pregunta en clave teórica.

\section{Aproximaciones para pensar la interpretación de los derechos sociales en la escolaridad de la niñez migrante}

Queremos dejar planteada una pregunta por los sentidos que adquiere la relevancia del niño como sujeto -de derechos, de inclusión- en un contexto en el que la legitimación de las necesidades de los niños no siempre se vincula al reconocimiento de las de sus familias. No se trata de "desconfiar a priori" del discurso de los derechos de la niñez; de hecho no abonamos a visiones instrumentalistas ingenuas que sólo ven en ellos o herramientas indiscutibles de emancipación, o evidentes meca- nismos de dominación (Reynolds et al., 2006). Por el contrario, los procesos de institucionalización de derechos de infancia se abordan en su complejidad y dimensión concreta cuando se analizan las configuraciones estratégicas y los contextos específicos en los que diversos grupos los despliegan (Reynolds et al., 2006, p. 294). Pero tenemos en cuenta que la penetración de los discursos de infancia en la región latinoamericana se produjo en el marco de la profundización de la desigualdad social, y las formas de privatización de las responsabilidades que se instalaron con los ajustes neoliberales (Llobet, 2008). Nos apoyamos también en los estudios que señalan el modo en que este paradigma puede desconectar la situación de los niños pobres de las condiciones de vida de su entorno, como aspecto estructurante de los sectores sociales a los que estos pertenecen (Llobet, 2011; Barna, 2012).

En segundo orden, desde nuestro punto de vista estos procesos deben situarse de plano en la discusión de las "minorías" jurídicas: el niño y el migrante como sujetos de derechos que se configuran en oposición al sujeto genérico (Vianna, 2008).

Los argumentos del ámbito jurídico enfatizan la vulneración de los derechos de los niños a los que se les niega la $\mathrm{AUH} u$ otras prestaciones sociales (Ceriani, Cyment y Morales, 2011; Serra, 2011; Goldar y Heffes, 2012). Sin desconocer que en estas disputas el lenguaje de derechos de la niñez asume un carácter estratégico, es importante atender a la jerarquización entre los niños y los migrantes como sujetos de derechos específicos que puede explicitarse en estas retóricas, una jerarquización que hemos registrado aparece en documentos de organismos de infancia (Martínez, 2014). Estas tensiones entre minorías jurídicas (Fonseca y Cardarello, 2005) nos lleva a dejar planteada la necesidad de problematizar la "doble condición" en el ámbito escolar. En este caso, recortando nuestra atención hacia los discursos institucionales, pudimos advertir en la escuela cierta asimetría entre "retóricas disponibles" de determinados sujetos de derechos (los niños) y la virtual ausencia de otras (migrantes). Esta observación implicaría reconocer, en primer orden, que la ley de migraciones vigente no se involucra en la forma en 
que se legitima la inclusión escolar de esta población. Sin embargo, nuestro interés en esta "asimetría" responde más a identificar el sentido que adquiere en un contexto donde las necesidades legítimas de los niños no siempre se equivalen con ( $\mathrm{y}$ a veces son disociadas de) las de sus adultos de referencia. Ante lo dicho, no es un simple dato de contexto que las políticas de protección social de los últimos diez años se definen como medidas de reparación frente a la dificultad de amplios sectores de la población en superar los condicionamientos estructurales para la inserción ciudadana, entre otras cuestiones el empleo formal (Feijoo y Corbetta, 2015). En particular, la AUH transforma la definición de política social porque incluye a grupos tradicionalmente excluidos del sistema de protección social, y por lo tanto es una extensión de las asignaciones familiares de las que habían estado excluidos históricamente los hijos de los trabajadores informales (Pautassi, Arcidiácono y Straschnoy, 2014).

Ante esto es central advertir que, en la escuela, ni la AUH ni los programas de transferencia de ingresos en general son asociados discursivamente a los condicionamientos estructurales que por otro lado se reconocen -como la informalidad y la explotación laboral-. Esto resulta más preocupante si se tiene en cuenta que se ha comprobado el fuerte impacto positivo de la AUH en cuanto al acceso de los niños de sectores más empobrecidos al derecho a la educación (Kliksberg y Novacovsky, 2015)7. No obstante, las ricas imágenes que relatan las docentes, que evidencian un conocimiento detallado de las condiciones de vida de estos niños y sus familias -fuertemente apoyadas en las economías informales a las que accede esta población como forma de subsistencia- se superponen al protagonismo de categorías morales (sacrificio, esfuerzo, desidia y abandono) sobre los individuos. Esta superposición advierte que lo que se asume como problema económico y social en el niño, puede

7 Estudio en el que también se ofrece evidencia empírica que desmiente las "presunciones" sobre desincentivo al empleo que circulan en imaginarios y debates públicos. desplazarse hacia el terreno de lo moral al referir a las "limitaciones" atribuidas a sus adultos de referencia. Resulta importante considerar que en el caso abordado, la construcción de exclusiones no parece recortarse en la desigualdad de status entre nacionales y extranjeros, sino que se despliegan otras clasificaciones -entre pobres sacrificados y pobres vagos, madres con "desidia"-. De hecho, estas distancias morales que los agentes estatales construyen en interacción con la población destinataria de las políticas, se vienen registrando en estudios de otros contextos de pobreza en Argentina (Villalta y Llobet, 2015). Si bien ello no implica omitir la forma en que la extranjería constituye una condición de ciudadanía específica permanentemente disputada en las interacciones contenciosas de los migrantes en las dependencias estatales (González y Plotnik, 2013), lo observado permite advertir procesos comunes que atraviesan a esta población migrante limítrofe y la población pobre en general, como las acciones o miradas "tutelares" de los agentes estatales sobre el desempeño de las mujeres "como madres" (Pautassi, Arcidiácono y Straschnoy, 2014).

\section{Conclusiones}

El reiterado discurso sobre las expectativas de movilidad social ascendente de los migrantes, adquiere un lugar central en la forma en que los docentes legitiman el acceso de los hijos de migrantes a la escuela pública, y un aspecto fundamental en este sentido es el reconocimiento de la condición estructural de informalidad que atraviesa a las familias de los niños. Recurrentemente señalado por los docentes, este punto de partida de muchas de las descripciones sobre las condiciones de vida de la población no es vinculado a las necesidades de las familias cuando "se interpreta" el percibimiento de programas de transferencia de ingresos. En concreto, las condiciones de informalidad y precariedad laboral son visibilizadas cuando se legitima la inclusión escolar de los niños migrantes, mientras que se las invisibiliza al interpretar otros derechos sociales a los que acceden las familias. 
En este sentido, hemos registrado que la reivindicación de la inclusión escolar y el merecimiento de los niños migrantes o hijos de migrantes a una educación de calidad, coexiste con formas de cuestionamiento más o menos explícitas de otros derechos sociales que percibe esta población, a través de clasificaciones morales de los destinatarios de las políticas. Recordamos también que los migrantes "argentinizados" son identificados en ocasiones con algunas de las predisposiciones moralmente cuestionables como la "desidia" o el "facilismo", pero también son vinculados a quienes expresan demandas, exigencias o expectativas de trato hacia la escuela. En este sentido, resaltamos que los discursos moralizantes sobre la predisposición al esfuerzo o el trabajo, -como categorías de percepción que responsabilizan a los individuos-, remiten a interacciones y contextos donde lo que se disputan son responsabilidades institucionales.

No podemos omitir que al momento de escribir este artículo, las retóricas estatales de la nueva gestión nacional de signo conservador, entrante a finales de 2015 , se han dedicado principalmente a justificar el recorte y ajuste de áreas estatales; notamos asimismo un temprano desplazamiento de la retórica de los derechos -desde donde precisamente se legitimaba la ampliación de la esfera estatal en los últimos años-. En estos nuevos contextos, apostamos a seguir reflexionando sobre el sentido que asume, en la escuela, el cuestionamiento de derechos sociales que apuntan a garantizar las condiciones mínimas necesarias para el acceso al derecho a la escolaridad.

\section{Referencias bibliográficas}

Barna, A. (2012). Convención Internacional de los Derechos Del Niño. Hacia un abordaje desacralizador. KAIROS. Revista de Temas Sociales. ISSN 1514-9331. http://www.revistakairos.org Ceriani.

Blanck, E. (2013). “Desigualdad educativa en la Ciudad de Buenos Aires: un análisis estructural de las políticas educativas desde un enfoque de derechos humanos". Asesoría General Tutelar, Buenos Aires. Eudeba.
Centro de Estudios Legales y Sociales -CELS- (2012). Cap. V. "Política migratoria y derechos humanos: consolidación de una agenda para proteger los derechos de los migrantes" Informe Derechos Humanos en Argentina, 325-348. Siglo Veintiuno Editores.

Ceriani Cernadas, Pablo, García, Lila, y Gómez Salas, Ana (2014). Niñez y adolescencia en el contexto de la migración. Principios, avances y desafíos en la protección de sus derechos en América Latina y el Caribe. REMHU, XXII (42), 9-28.

Ceriani Cernadas, Cyment, P. y Morales, D. (2011). "Migración, derechos de la niñez y Asignación Universal por Hijo: las fronteras de la inclusión social". Ponencia disponible en http://www. derhuman.jus.gov.ar/conti/2011/10/mesa_2/ ceriani_cyment_morales_mesa_2.pdf

Cerruti, M. y Binstock, G. (2012). Los estudiantes inmigrantes en la escuela secundaria. Integración y desafíos. Buenos Aires: Fondo de las Naciones Unidas para la Infancia (UNICEF).

Cravino, M. C. (2008). Relaciones entre el mercado inmobiliario informal y las redes sociales en asentamientos informales del área metropolitana de Buenos Aires. Territorios, 18-19, 129-145. Bogotá, Colombia.

Domenech, E. (2007). La agenda política sobre migraciones en América del Sur: el caso de la Argentina. Revuee Europeene des migrations internationales, 23(1). Disponible en http://remi.revues. org/3611?lang=en

Douzinas, C. (2006). El fin(al) de los derechos humanos. Anuario de Derechos Humanos. Nueva Época, 7. T. 1, 309-340.

Feijoo, M. del C. y Corbetta, S. (2015). La institución escolar y la implementación de la Asignación Universal por Hijo (AUH). En: Prácticas pedagógicas y políticas educativas. Investigaciones en el territorio bonaerense. Buenos Aires: Editorial Universidad Pedagógica (UNIPE).

Fonseca, C. y Cardarello, A. (2005). Derechos de los más y menos humanos. En Tiscornia, S. y M. V. Pita (Eds.), Derechos humanos, tribunales y policías en Argentina y Brasil. Estudios de antropología jurídica. Buenos Aires: Antropofagia.

Fraser, N. (1999). La lucha por las necesidades. Esbozo de una teoría crítica socialista-feminista de la cultura política del capitalismo tardío. Debate 
feminista. Debate Feminista, 3, 3-40. Retrieved from http://www.jstor.org/stable/42623971

Gil Araujo, S., Morales, D., Novaro G., Pacecca, M.I, Kohen N. y Mera, C. (2013). Migraciones e igualdad/desigualdad. Argumentos. Revista de crítica social. ISSN 1666-8979 No15 pp. 1-30

Goldar, F. y Heffes, E. (2012). “Niños, migrantes e iguales en el Sistema Interamericano: El interés superior en la aplicación de los DESC". Ponencia al Congreso de Derecho Público. Democracia y Derechos. Disponible en http://www.derecho. uba.ar/institucional/deinteres/derechos-huma nos-fernando-goldar-y-ezequiel-heffes.pdf

González, A. Plotnik, G. (2013). Nosotros-otros. Violencia simbólica y representaciones sociales sobre el migrante internacional. Un análisis en las instituciones educativa y judicial de la Ciudad de Buenos Aires y Gran Buenos Aires. Argumentos. Revista de crítica social. ISSN 1666-8979. No15 pp. 150-175

Guber, R. (1991). El salvaje metropolitano. A la vuelta de la antropología posmoderna. Buenos Aires: Legasa.

Kliksberg, B., Novacovsky, I. (2015). El gran desafío. Romper la trampa de la desigualdad desde la infancia. Aprendizajes de la Asignación Universal por Hijo. Buenos Aires: Biblos.

Llobet, V. (2008). Las políticas sociales para la adolescencia y los procesos de ampliación de derechos. En: Granda Aguilar (Comp.), Pobreza, exclusión y desigualdad (pp. 317-334). Quito: FLACSO.

(2011). Las políticas para la infancia y el enfoque de derechos en América Latina. Algunas reflexiones sobre su abordaje teórico. Fractal: Revista de Psicología, 23(3), 447-460.

Martínez, L. (2011). Discursos sobre la migración en el contexto escolar: una exploración de las relaciones entre las prácticas institucionales y las concepciones de los niños migrantes. En: Gabriela Novaro (Coord.), La interculturalidad en debate. Procesos de identificación y experiencias formativas en niños indígenas $y$ migrantes. Buenos Aires: Biblos.

Martínez, L. (2014). Niñez, migración y derechos: aportes para un abordaje antropológico. Revista Sociedad y Equidad, 0 (6). doi:10.5354/0718-9990.2014.27268

Neufeld, M. R. y Thisted, J. A. (1999). El crisol de razas hecho trizas: ciudadanía, exclusión y sufri- miento. En: Neufeld, María Rosa y Thisted, Jens Ariel (Comps.), De eso no se habla... los usos de la diversidad sociocultural en la escuela. Buenos Aires: Eudeba.

Novaro, G. (2012). Niños inmigrantes en Argentina: nacionalismo escolar, derechos educativos y experiencias de alteridad. Revista Mexicana de Investigación Educativa, 17(53). Versión impresa ISSN 1405-6666 RMIE México.

Novaro, G. y Beheran, M. (2011) Apuntes introductorios para abordar la escolarización de los niños migrantes. En: Gabriela Novaro (Coord.), La interculturalidad en debate. Procesos de identificación y experiencias formativas en niños indígenas y migrantes. Buenos Aires: Biblos.

Pacecca, M. I. y Courtis, C. (2010). Género y trayectoria migratoria: mujeres migrantes y trabajo doméstico en el Área Metropolitana de Buenos Aires. Papeles de Población, 16(63), 155-185, enero-marzo. Universidad Autónoma del Estado de México.

Pautassi, L. Arcidiácono, y Straschnoy, M. (2014). Condicionando el cuidado. La asignación universal por hijo para la protección social en Argentina. Iconos. Revista de Ciencias Sociales, 50. ISSN: 1390-1249. Quito: FLACSO.

Reynolds P., Nieuwenhuys y Hanson, K. (2006). Refractions of Children's Rights in Development Practice: A view from anthropology. Childhood 13, 291. London. Sage Publications.

Rockwell, E. (2009). La experiencia etnográfica. Historia y cultura en los procesos educativos. Buenos Aires: Paidós.

Serra, L. (2011). La migración y los derechos del niño. Revista Electrónica del Instituto de Investigaciones "Ambrosio Gioja" Año V. Disponible en http://www.derecho.uba.ar/re vistagioja/articulos/R000E01A005_0026_p-dinternacional.pdf

Unla-UNICEF. (2013). Niñez, migraciones y derechos humanos en Argentina. "Estudio a 10 años de la ley de migraciones". EDUNLa

Vianna, Adriana (2008). El mal que se adivina. Policía y minoridad en Río de Janeiro, 1910-1920. Buenos Aires: Ad-Hoc.

Villalta, C. y Llobet, V. (2015). Resignificando la protección. Los sistemas de protección de derechos de niños y niñas en Argentina. Revista Latinoamericana de Ciencias Sociales, Niñez y Juventud, 13(1), 167-180. 